\title{
Restructuring and reorienting English speaking skills courses for initial English teacher education in Indonesia
}

\author{
Chairil Anwar Korompot \\ Universitas Negeri Makassar \\ English Department \\ Makassar, South Sulawesi, Indonesia \\ chairilkorompot@gmail.comline
}

\begin{abstract}
This paper examines the recent curricular change made to the mandatory English speaking skills courses at an initial teacher education (ITE) institution in Indonesia. The institution is following what seems to be a nation-wide trend of replacing the traditional graded English speaking skills courses (GESSCs) with integrated-English-skills courses (IESCs) and/or functional English speaking skills courses (FESSCs). This paper argues for the need to restructure the English speaking skills courses for future English teachers based on "intensive" speaking (IS) and extensive speaking (ES) approaches in addition to IESCs, thereby reinstating GESSCs as mandatory courses. It also argues for reorienting the trendy FESSCs as elective courses that will complement rather than eliminate the traditional GESSCs in the future curriculum
\end{abstract}

Keywords-English language; initial teacher education

\section{INTRODUCTION}

English language (EL) skills, namely listening, speaking, reading and writing, have been a part of successive and various curricula of EL teacher-preparation programs at initial teacher education (ITE) institutions in Indonesia. The EL skills courses are viewed as essential for developing future EL teachers' proficiencies, which are a contributing factor to their teaching skills and confidence [1]. Among those EL skills courses are the mandatory speaking skills courses offered in the first and second years of undergraduate English Language Education program.

For decades, EL speaking skills have been taught as part of a separated-skills curriculum with graded English speaking skills courses (GESSCs). However, systemic functional linguistic approach in language education [2], institutions are now gradually replacing GESSCs with integrated-skills curriculum and functional English speaking courses (FESSCs). This is in addition to the introduction in 2012 of the National Competency Framework of Indonesia and its elaboration by the Indonesian Association of Tertiary Institutions of English Language Education.

This is what is happening at one major government ITE institution in Indonesia. In this institution, the GESSCs, namely Speaking I (originally taught in the 1st semester), Speaking II (in the 2nd semester), Speaking III (3rd semester), and Speaking IV (4th semester), have been replaced by an integrated EL skills course called Intensive Integrated English Course (IIEC) in the 1st semester and by three English speaking skills courses called Basic Speaking (currently taught in the 2nd semester), Intermediate Speaking (in the 3rd semester), and Advanced Speaking (4th semester). There are indications, however, that these three "new" courses would soon be replaced by three FESSCs, i.e Speaking for Everyday Communication (to be taught in the 2nd semester), Speaking for Group Activities (3rd semester), and Speaking for Formal Setting (4th semester).

A similar move is taking place at various ITE institutions across Indonesia as they are revising their curricula. They have changed their graded-/separated-skills courses with integrated-skills plus functional EL skills courses. However, as much as it constitutes an enthusiastic response to the latest global developments of SFL in language education, this recent movement warrants critical examination, which I, having spent many years teaching English speaking skills to thousands of ITE students in the Indonesian EFL context, felt compelled to do.

\section{GESSCS VS. FCESSCS}

There are fundamental differences between the traditional GESSCs (i.e. Speaking I through to Speaking IV) and the trendy FESSCs (e.g. Speaking for Everyday Communication etc.). In this section I will try to analyze these differences in terms of their purpose, contents, and activities using my firsthand experience as an EL teacher educator.

In terms of purpose, GESSCs aim to develop and improve students' spoken EL skills in stages, i.e. beginning, intermediate, upper-intermediate, and advanced levels. These levels imply the trajectory of students' EL development that acknowledges students' EL learning processes. FESSCs, on the other hand, aim at enabling students to develop their English speaking skills in certain or specific settings or discourses in which the communicative use of the target language is believed to occur naturally.

As far as contents go, GESSCs teach students according to their levels of English proficiency using materials organized and methodologies developed around increasing levels of 
difficulty. In FESSCs, however, even though the courses are structured according to levels of functional/contextual complexities, students doing the same course are assumed to be at roughly the same level of proficiency and have already had what it takes to understand and use English according to the function/context at that level.

As for classroom activities, GESSCs' students are taught according to their levels of English and the materials' levels of difficulty. At the beginning and pre-intermediate levels, activities are teacher-led for the most part to ensure that students have solid basic knowledge, skills, and attitudes related to English speaking skills. At the intermediate and especially at advanced levels, activities are conducted to achieve more complex communicative tasks, and students are engaged in more independent, student-centered activities to carry out their tasks. In contrast, classroom activities at each stage of FESSCs may be either teacher-centered or studentcentered, or both, and are carried out to accomplish communicative tasks that revolve around the theme of the specific linguistic function/context in which English is used (i.e. in everyday communication, for group activities, and in formal setting).

Based on my professional experience, one of the implications of the differences discussed above is that both GESSCs and FESSCs have their own rightful places in the ITE curriculum. Therefore, instead of replacing GESSCs with FESSCs, I argue that the two sets of courses should co-exist and complement each other and that the former should be restructured and the latter be reoriented. The rationale for this argument is described in the ensuing sections.

\section{RESTRUCTURING GESSCS}

Restructuring GESSCs means that the traditional speaking courses would be here to stay but with "new" approaches and complemented by IESCs and FESSCs. The following sections discuss the "new" approaches to teaching GESSCs referred to as intensive speaking (IS) and extensive speaking (ES). These were inspired by works done by Bamford and Day [3], [4] and argued that in extensive reading (ER), which is defined as an alternative to intensive reading (IR).

\section{A. IS}

The notion of IS has been almost unheard of until now. In a nutshell, IS is the speaking version of IR. The lack of literature on IS makes it necessary to bring IR into perspective when discussing IS.

Bamford and Day explain that intensive reading (IR) engages students in "careful reading of shorter, more difficult foreign language texts with the goal of complete and detailed understanding [3]." In other words, IR is the traditional way of teaching reading. It is characterized by the employment of reading materials chosen by the teacher, reading and related activities as well as grammar and vocabulary exercises led by the teacher within the confines of the classroom, comprehension-questions, and assessment done by the teacher [5].
By extension, IS may be defined as an approach that engages students in intensive teacher-led/teacher-assisted activities to develop proficiencies in the EL oral component skills and elements with the goal of complete mastery of oral EL proficiencies. Students practice the oral component skills and elements by pronouncing segmental sounds, suprasegmental sounds, and complete utterances; reading aloud or performing oral discourse and communicative tasks; and using listening, reading, and writing skills in their speaking activities, etc. Therefore, the teacher "runs the show" as he or she plans and chooses the materials, guides and manages the classroom activities and exercises, gives corrective feedback, and carries out the assessment. These characteristics have a lot in common with the "otherregulation" approach of Thornbury (2005) in teaching speaking skills which aims at promoting awareness-raising activities and appropriation activities.

In summary, "intensive speaking/other-regulated" approach should be the precondition of freer or more challenging speaking courses. Therefore it is applicable to teaching the courses of Speaking 1 (or Basic Speaking) and Speaking 2 (or Pre-Intermediate Speaking) to the 1st and 2nd semester freshmen at ITE institutions.

\section{B. $E S$}

Unlike IS, ES is relatively more visible in the literature on second or foreign language speaking instruction. ES is a new addition to the small yet growing body of literature (notably Sun 2012 and $\mathrm{Gu} \&$ Reynolds 2013) that extends the scholarship of extensive reading (ER) to speaking skills. ER is defined as "the independent reading of a large quantity of material for information or pleasure" (Renandya, Jacobs \& Yu 1998). This is characterized by ten key principles which were interpreted by $\mathrm{Gu}$ and Reynolds (2013) to develop their 10 principles of ES as shown in Table 1 below.

Table 1. ES Principles based on Day \& Bamford's (2002) ER Principles*

\#1 Schedule daily time for ES work, allow additional talks via the internet.

\#2 Suggest lots of topics - related/not related to class themes.

\#3 The language produced by students must be at or below their level.

\#4 Always allow "free topic" talks.

\#5 Make activities ungraded.

\#6 Make activities required, but ungraded.

\#7 Allow students to produce independently (in a different room than the rest of the class)

\#8 Not silent, of course, but talks are individual (with posttalk feedback from teacher, but not other students.

\#9 Teachers create talks on the scheduled class topics for students to listen to and interact with.

\#10 Teachers do not grade but do provide positive feedback $\&$ encouragement 
* Adapted from Gu \& Reynolds (2013).

In essence, Gu \& Reynolds' ES principles share the approach to teaching reading skills framed under the theme of autonomy. Thornbury (2005) describes it as a stage achieved when learners are in a position to 'appropriate' the new knowledge, or "mak[ing] it their own...[and] gradually...function independently in a state of selfregulation" [6]. The 'self-regulated' activities in ES may range from presentation and talks, stories, jokes and anecdotes, drama, role-play, and simulation, discussions and debates, conversation and chat, and outside-class speaking [6].

In sum, this "ES/self-regulated" approach is freer yet more challenging than "IS/other-regulated" approach. Therefore it is applicable to teaching Speaking 3 (or Intermediate Speaking) and Speaking 4 (or Advanced Speaking) for the 3rd and 4th semester ITE students' speaking skills.

\section{REORIENTING FESSCS}

Assuming that the restructuring (or reinstatement) of GESSCs would be considered in the next curricular revision at the ITE institution referred to in this article, reorienting FESSCs would be in order. Given their characteristics, FESSCs should be reoriented from being mandatory courses replacing GESSCs to being elective courses complementing GESSCs.

\section{CONCLUSION}

In this paper I have discussed the merits of IS/other regulated approach and ES/self-regulated approach in the English speaking curriculum of ITE in the Indonesian context. Rather than being viewed in the dichotomous light as some articles in the ER literature have treated them, the two approaches are presented as complementary ones in this paper with IS courses being the first part and ES courses being the second part of the mandatory English speaking skills curriculum. This is referred to as restructuring and reinstating GESSCs in the ITE curriculum. Furthermore, the paper argues for the importance of reorienting the trendy FESSCs to become elective courses instead of replacing GESSCs in the English speaking skills curriculum at the ITE institution.

\section{References}

[1] J. C. Richards, "Competence and performance in language teaching," RELC J., vol. 41, no. 2, pp. 101-122, 2010.

[2] M. A. K. Halliday, "Towards a language-based theory of learning," Linguist. Educ., vol. 5, no. 2, pp. 93-116, 1993.

[3] J. Bamford and R. R. Day, "Extensive reading: What is it? Why bother?," Lang. Teach., vol. 21, pp. 6-8, 1997.

[4] R. R. Day, J. Bamford, W. A. Renandya, G. M. Jacobs, and V. W.-S. Yu, "Extensive reading in the second language classroom," RELC J., vol. 29, no. 2, pp. 187-191, 1998.

[5] F. Al-Homoud and N. Schmitt, "Extensive reading in a challenging environment: A comparison of extensive and intensive reading approaches in Saudi Arabia," Lang. Teach. Res., vol. 13, no. 4, pp. 383401, 2009.

[6] S. Thornbury, How to teach speaking. Longman, 2005.

[7] S. Gu and E. D. Reynolds, "Imagining extensive speaking for Korean EFL,” Mod. English Educ., vol. 14, no. 4, pp. 81-108, 2013. 